\title{
Testing a radical theory
}

$\mathbf{T}$ he paper by Keller and Vosshall on page 337 of this issue is unusual; it describes a refutation of a theory that, while provocative, has almost no credence in scientific circles. The only reason for the authors to do the study, or for Nature Neuroscience to publish it, is the extraordinary-and inappropriate-degree of publicity that the theory has received from uncritical journalists.

The theory, from Luca Turin (formerly of University College London), concerns the mechanism of olfactory transduction. Olfaction is not well understood compared to the other senses, but most experts believe that odorant molecules bind to specific receptors through conventional molecular interactions, causing a conformational change in the receptor that leads to activation of intracellular signals. Admittedly there are no clear demonstrations (apart from one study $^{1}$ in C. elegans) that a specific receptor binding to an odorant mediates the perceptual response to that odorant, and there are some anomalies, such as molecules that smell the same despite their lack of chemical similarity. However, this could be explained through subsequent neural processing (if for example receptors with different specificity were to activate common targets within the brain).

Turin proposed a very different theory, namely that olfactory receptors act like a spectroscope to detect intramolecular vibrations within the odorant molecule. According to this idea, the perceptual quality of an odorant is determined not by its shape but by its vibrational spectrum. This would be of great importance if true, but radical ideas require strong evidence, which Turin did not provide. Nor did he provide a detailed explanation of how these molecular vibrations could lead to neural activation.

The magician James Randi, debunker of paranormal claims, once said that if you claim to have a goat in your back yard, people will probably believe you, but if you say you have a unicorn, you must expect closer scrutiny. The editors at Nature used to classify manuscripts on a 'zoological scale' that ranged from goats to unicorns, and Turin's paper was toward the far end of that scale. Despite the forcefulness of his assertions, most scientists in the field were unconvinced by his proposal. Thus his paper was rejected by Nature, and it was eventually published (without review, according to Turin's own account) by Chemical Senses in 1996.

Turin's theory would probably have vanished into obscurity but for two coincidences. First, one of his former students had become a producer for the BBC, and she decided to make a TV documentary about him. Second, he had a chance encounter with writer Chandler Burr, who was so taken with the theory that he wrote a popular book about it. The Emperor of Scent, which appeared in 2002, is effectively a mouthpiece for Turin's views, and it is intensely hostile to the scientific establishment. It has attracted wide attention, and with the exception of a scathing review in this journal from Avery Gilbert ${ }^{2}$, the reviews have been almost uniformly favorable. The book is seductively written, and it was recently reissued in paperback, complete with a readers' guide to promote book club discussions.
The villains of Burr's book include many of the leading figures in the olfactory community, who are portrayed as ignorant and incompetent reactionaries, along with the journal editors who rely on their advice. Burr's overall verdict is that Turin's failure to convince the scientific establishment of his views reflects "scientific corruption... in the most mundane and systemic and virulent and sadly human sense of jealousy and calcified minds and vested interests."

Many olfactory researchers were dismayed by the book and by the apparent willingness of the media to accept Burr's verdict. Keller and Vosshall were sufficiently upset that they decided to put Turin's theory to an experimental test. As described in their paper, they tested three claims of the vibration theory, all of which feature prominently in Burr's book. The experiments were conducted double-blind, and in all three cases the results were negative. Turin himself had no role in designing the study, and one could debate (as Turin probably will) whether this study constitutes a definitive refutation of his theory. A conservative statement would be that Turin's claims are not reproducible based on the information provided in his own publications. At the least, the burden of proof for confirmation of his theory is now unambiguously transferred to Turin, where it should have been all along.

In some sense it does not matter whether the public believes in the vibrational theory of olfaction; the truth will eventually come out. But of course this is not just about olfaction. It is about the public credibility of the scientific process and the biases that affect science reporting in the popular press. It is disturbing that Emperor of Scent received so much favorable publicity from reviewers who were ill qualified to judge its scientific content. The New York Times and The Washington Post, for instance, assigned it to their movie critic and fashion critic, respectively.

The media loves controversy, and ever since David and Goliath, the story of a lone hero taking on the establishment has had enduring appeal. Of course, radical ideas from outside the mainstream do occasionally turn out to be right. Of course scientists are sometimes excessively attached to conventional ideas. But in science at least, the mainstream view is usually based on the accumulation of evidence over many years. Journalists are trained to report both sides of any argument, but this can be misleading when both sides are not equally credible.

A mature body of scientific theory is like a large building, and the impulse to demolish it is often little more than a form of intellectual vandalism, an expression of frustration by those who did not succeed as architects. Some buildings outlive their usefulness, of course, but the threshold for knocking them down should be high. We hope that the paper from Keller and Vosshall will serve as a reminder of why that's so.

\footnotetext{
1. Sengupta, P., Chou, J.H. \& Bargmann, C.I. Cel/ 84, 899-909 (1996).

2. Gilbert, A.N. Nat. Neurosci. 6, 335 (2003).
} 